\title{
Clinical and Laboratory Profile of Newly Diagnosed HIV- Infected Patients Attending ART Centre, Government Thiruvannamalai Medical College Hospital, Thiruvannamalai
}

\author{
Dr. S. Sivakumar ${ }^{1}$ M.D., Dr. B. Prabakar ${ }^{2}$ M.D., \\ ${ }^{1}$ Associate Professor, Department of General Medicine, Government Thiruvannamalai \\ Medical College and Hospital \\ ${ }^{2}$ Associate Professor, Department of General Medicine, Government Thiruvannamalai \\ Medical College and Hospital
}

\begin{abstract}
:
Introduction: Indian subcontinent has one of the highest HIV prevalence rates globally as per WHO. The HIV has reached epidemic proportions in our country and characterised by high rates of morbidity and mortality. Aim of the study: To document, the clinical profile, the laboratory profile, clinical staging and immunological staging based on CD4 count, in 100 randomly selected newly diagnosed HIV infected patients attending ART centre, Government Thiruvannamalai Medical College Hospital, Thiruvannamalai from January 2016 to July 2016.

Materials: 100 randomly selected newly diagnosed HIV infected patients attending the ART centre, Government Thiruvannamalai Medical College Hospital, Thiruvannamalai

Duration of the study: 7 MONTHS

Type of study: Descriptive study

Sample size: 100

Inclusion criteria: >15 years of age , HIV seropositive, Newly registered in ART centre at Government Thiruvannamalai Medical College Hospital, Thiruvannamalai between January 2016 to July 2016., Not on HAART

Exclusion criteria: $<15$ years of age, Already on HAART.

Methodology: Informed consent was obtained for taking part in this study. Patient information, medical history including diagnosis of HIV-infection, opportunistic infections and other HIV-related disorders was obtained from the patient medical records using predesigned data collection forms. Clinical staging of patients was done based on the World Health Organisation (WHO) criteria for the Clinical Staging of Established HIV Infection. Investigations included full blood count, liver function tests, renal function tests and CD4 count.

Statistical analysis: Statistical analysis was done using simple percentage analysis.

Results: $41 \%$ of the study group population were asymptomatic (Stage 1). $43 \%$ of them were in the clinical stage 3. Only 3\% were in the clinical stage 4. The most common symptom of the patients in the study population is fever (28\%), followed by cough (24\%), dysphagia (15\%), diarrhoea (15\%), eight loss (14\%), loss of appetite (12\%) and abdominal pain (3\%).

Conclusion: Most of the newly diagnosed HIV infected patients belong to the age group of 31 to 45 years of age. There is a positive correlation between the clinical stage and the immunodeficiency based on CD4 count. Fever is the most common symptom in newly diagnosed HIV infected patients, followed by cough. Tuberculosis is the most common opportunistic infection followed by oral candidiasis. All patients with HIV infection should be screened for Tuberculosis and vice versa.
\end{abstract}

Key words: HIV infected patients, opportunistic infection, clinical staging, CD4 count.

\section{Introduction}

Humans have seen the emergence of many new diseases throughout the history. In the $20^{\text {th }}$ century the disease which came to the fore and made the human race panic the most was Acquired Immune deficiency Syndrome (AIDS), which is caused by Human Immunodeficiency Virus (HIV). The disease surfaced in the 1980s, and three decades later, our combat with the disease is still on. Hence AIDS/HIV remains one of the most dreaded public health challenges.

Although the overall rate of new infections appears to decline, epidemics among key populations continue to grow alarmingly. This includes injection drug users (IDU), homosexuals and sex workers. Remarkable progress has been made in such populations over the last decade-yet significant challenges remain. The absence of a cure or preventive vaccine to the disease has had its negative effect on economy and development of various developing countries like India. But a positive response from the government, NGOs 
and WHO have effectively brought down the transmission rates among the most vulnerable populations in India. Many studies contribute to the evidence base for emphasis on prevention as the most cost beneficial and effective national response.

\section{Aim of the study}

\section{To document,}

1) The clinical profile

2) The laboratory profile

3) Clinical staging

4) Immunological staging

In 100 randomly selected newly diagnosed HIV infected patients attending ART centre, Government Thiruvannamalai Medical College Hospital, Thiruvannamalai from January 2016 to July 2016.

\section{Study $1^{[15]}$}

\section{Previous studies}

Thinyane et al conducted a prospective observational study, Clinical Profiles of HIV-Infected; HAART-Naive Patients Admitted to a Tertiary Level Hospital in Maseru, Lesotho, at Queen Elizabeth II (QE II) Referral Hospital in Maseru, Lesotho in South Africa a high prevalent country for HIV. QEII Hospital is a public sector tertiary level hospital which also functions as the national referral hospital. The study population included consecutive 105 adult patients (> 15 years) wards between July and October 2010. Patients were included if they tested positive for HIV(either known to be people living with HIV prior to admission or tested positive following admission), not receiving highly active anti-retroviral therapy (HAART) and admitted for the treatment of HIV-related disorders.

The most common symptom was cough which was followed by weight loss or wasting and generalised weakness. The commonest opportunistic infection was tuberculosis which was followed by oral candidiasis and pneumonia. The most common non-infectious HIV-related disease was anaemia. 5 patients were diagnosed with symptomatic HIV associated nephropathy and 1 patient with Kaposi Sarcoma .59\% was in Stage 3 and $41.0 \%$ were in Stage 4 of HIV infection. More than two thirds of the study participants had anaemia.

\section{Study $2^{[16]}$}

Nashaba et al did a study on Clinical Profile of HIV/AIDS-infected Patients admitted to a New Specialist Unit in Dhaka, Bangladesh - A Low-prevalence Country for HIV. This was a retrospective study on HIV positive patients admitted in a hospital in Dhaka. The aim of the study was to find the common opportunistic infections prevalent in HIV positive patients in that population and the status of CD4 count in them. Most of the population studied were adults $(>94 \%)$. Tuberculosis was the most common opportunistic infection which was found in the study population. Others common opportunistic infections were oral or oesophageal candidiasis, pulmonary infections and herpes zoster. Other common clinical manifestations of the disease recorded were weight loss, diarrhoea, lymphadenopathy and fever. With respect to CD4 count data, the largest number of patients was in the group with CD4 counts from 51 to 200 cells $/ \mu \mathrm{L}$ which constituted $31 \%$. The next largest group had CD4 counts of above 350 cells $/ \mu \mathrm{L}$ which constituted $26 \%$. Although those with a CD4 count of $<50$ cells $/ \mu \mathrm{L}$ represented $24 \%$ of the cohort, $62 \%$ of deaths were in this group of patients, indicating high morbidity and mortality associated with low CD4 counts, as reported in various other studies.

\section{Study 3}

Chakaravarthy et al conducted a study on on Clinico-epiemiological Profile of HIV Patients in Eastern India In this study, 438 HIV positive patients attending the outpatient clinic of Sir Sundar Lal Hospital, Institute of Medical science, Banarus Hindu University were enrolled. Of these 354 were males (mean CD4 count $179 \pm$ 9.3 cells $/ \mu 1$ ) and 84 were females (mean CD4 count $323 \pm 28.26$ cells/ $\mu 1$ ). The average age of the study subjects during the time of diagnosis was 32.6 years. The commonest mode of transmission was heterosexual contact in $80.4 \%$ patients followed by blood transfusion in $2.5 \%$. Among the male patients, $71.5 \%$ were found to be migrant workers. Fever (70.6\%), weight loss (53.3\%), chronic diarrhea (43.9\%) and cough (40.3\%) were the common presenting symptoms. Out of the 438 patients, $66.4 \%$ had opportunistic infections at the time of reporting to the hospital. The most common opportunistic infection was tuberculosis $(38.8 \%)$ which was followed by oropharyngeal candidiasis $(20.3 \%)$ and diarrhea (12.7\%). CD4 count was inversely proportional to the number of symptoms and opportunistic infections. 
Study $4^{[17]}$

Kaiser et al conducted a study on Clinical Profile of HIV/Aids Patients in Srinagar, Kashmir, India. The aim of the study was to assess the number of seropositive HIV patients enrolled in Government medical college and other associated hospitals in Srinagar, Kashmir, India, common signs and symptoms, age and sex distribution, modes of transmission and different types of opportunistic infections. The mean age of these patients were found to be $34.45 \pm 8.40$ with a higher male is to female ratio at 7:1.The summit incidence was found in the age group of 30-39yrs of age. Major group of HIV positive patients belonged to patients working as security personnel followed by migrant labourers and housewives. Sexual transmission was the main mode of transmission (90.7\%)followed by homosexual transmission ( $4.7 \%$ ). $78.9 \%$ of patients had fever of greater than 1 month duration, 35.1 \% had weight loss and 33.5\% had diarrhoea. Tuberculosis and oral/oesophageal/genital candidiasis were the most common opportunistic infection followed herpes zoster and varicella zoster.

Study $5^{[18]}$

Jayant et al conducted a study on Clinico-epidemiological profile of HIV patients attending ART centre in rural Western Maharashtra, India, which was a cross-sectional study, conducted at ART centre of a rural tertiary care hospital, situated in Maharashtra, India, from the March of 2011to September 2011. The study revealed that the most common presenting complaints were weight loss, fever, cough, and chronic diarrhoea. The majority of the patients in the study belonged to the sexually active age group of 20 to 40 years of age. Heterosexual contact was the commonest mode of acquiring the infection. Tuberculosis (62\%) was the most common opportunistic infection which was followed by pneumosystis carinii pneumonia, herpes zoster, malignancy, candidiasis, neurological disorders and ophthalmic manifestations. It was found that as the CD4 count decreased, incidence and the number of opportunistic infections in patients increased. As per the WHO staging $42.5 \%$ patients were in stage 3

\section{Materials:}

\section{Materials and Methods}

100 randomly selected newly diagnosed HIV infected patients attending the ART centre, Government Thiruvannamalai Medical College Hospital, Thiruvannamalai from January 2016 to July 2016.

Duration of the study: 7 Months

Type of study: Descriptive study

Sample size: 100

\section{Inclusion criteria:}

- $>15$ years of age

- HIV seropositive

- Newly registered in ART centre at GTVMCH between January 2016 to July 2016

- Not on HAART

\section{Exclusion criteria:}

- $\quad<15$ years of age

- $\quad$ Already on HAART

\section{Methodology}

Informed consent was obtained for taking part in this study. Patient information, medical history including diagnosis of HIV-infection, opportunistic infections and other HIV-related disorders was obtained from the patient medical records using predesigned data collection forms. Clinical staging of patients was done based on the World Health Organisation (WHO) criteria for the Clinical Staging of Established HIV Infection. Investigations included full blood count, liver function tests, renal function tests and CD4 count.

\section{Statistical Analysis}

Statistical analysis was done using simple percentage analysis.

\section{Observations and Results}




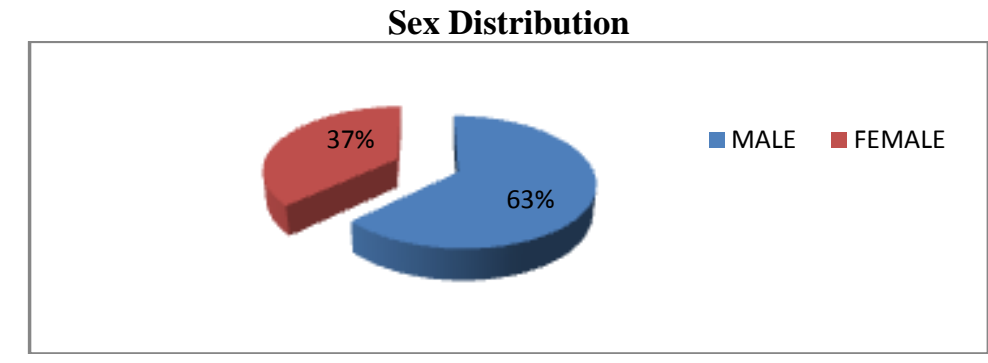

\begin{tabular}{|c|c|c|}
\hline GENDER & NUMBER & PERCENTAGE \\
\hline MALE & 63 & 63 \\
\hline FEMALE & 37 & 37 \\
\hline
\end{tabular}

In this study the number of males $(63 \%)$ included in the study were more than the females $(37 \%)$.

Age Distribution

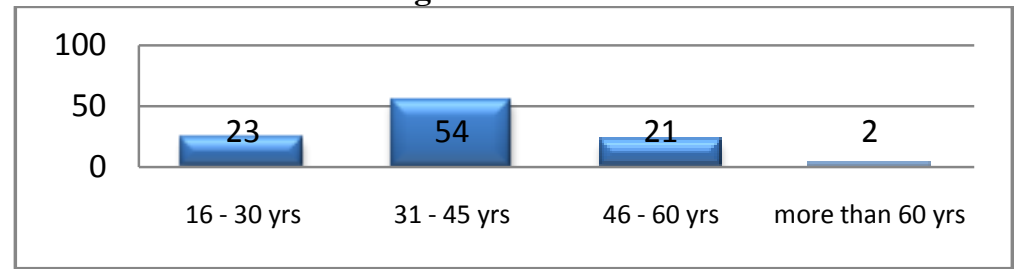

\begin{tabular}{|c|c|c|}
\hline AGE RANGE & NUMBER & PERCENTAGE \\
\hline $16-30$ YRS & 23 & 23 \\
\hline $31-45$ YRS & 54 & 54 \\
\hline $46-60$ YRS & 21 & 21 \\
\hline MORE THAN 60 YRS & 2 & 2 \\
\hline
\end{tabular}

More than half of the population in the study were in the age group of 31 to 45 years of age.

Sex And Age Relationship (Males - Percentage)

\begin{tabular}{|c|c|c|}
\hline & MALES & $\begin{array}{r}16-30 \text { YRS } \\
31 \text { - } 45 \text { YRS } \\
46-60 \text { YRS }\end{array}$ \\
\hline AGE RANGE & NUMBER & PERCENTAGE \\
\hline $16-30$ YRS & 11 & 17.46 \\
\hline $31-45$ YRS & 35 & 55.55 \\
\hline $46-60$ YRS & 15 & 23.80 \\
\hline MORE THAN 60 YRS & 2 & 3.17 \\
\hline
\end{tabular}

Out of the number of males studied, $55.55 \%$ were in the age group of 31 to 45 years of age.

Sex And Age Relationship (Females - Percentage)

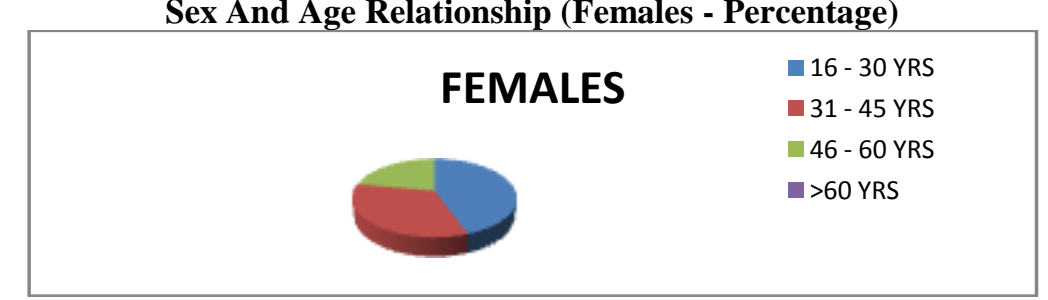

\begin{tabular}{|c|c|c|}
\hline AGE RANGE & NUMBER & PERCENTAGE \\
\hline $16-30$ YRS & 12 & 32.43 \\
\hline $31-45$ YRS & 19 & 51.35 \\
\hline $46-60$ YRS & 6 & 16.21 \\
\hline MORE THAN 60 YRS & 0 & 0 \\
\hline
\end{tabular}

More than half of the females were in the age range of 31 to 45 yrs of age. 


Literacy - Frequency Distribution
\begin{tabular}{|l|c|c|c|}
\hline \multicolumn{1}{|c|}{ LITERACY } & MALE & FEMALE & TOTAL \\
\hline LITERATES & 53 & 24 & 77 \\
\hline ILLITERATES & 10 & 13 & 23 \\
\hline
\end{tabular}

About $77 \%$ of the patients were literates and the rest were illiterates.

LITERACY
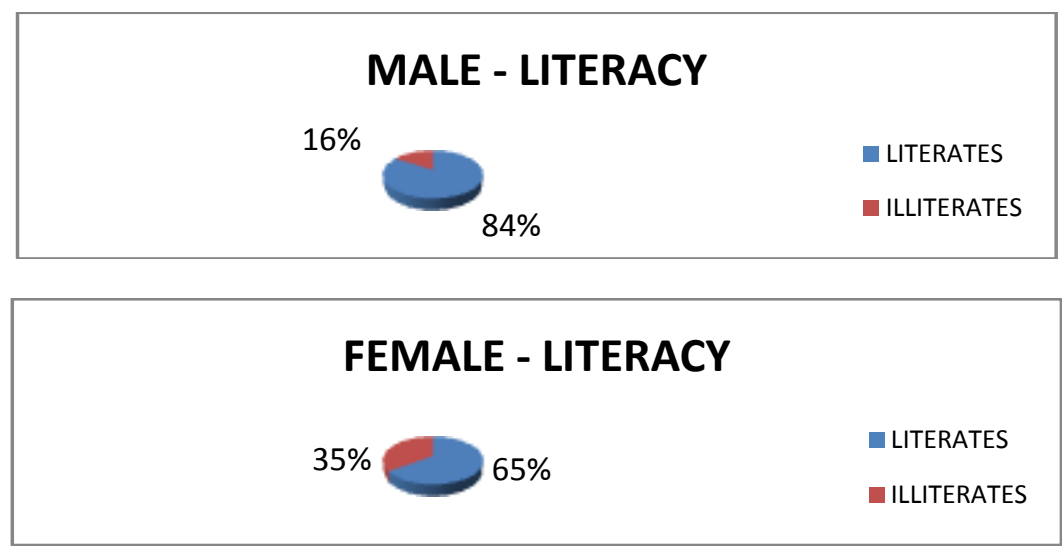

The percentage of illiteracy was more in the females when compared to the males within the study group.
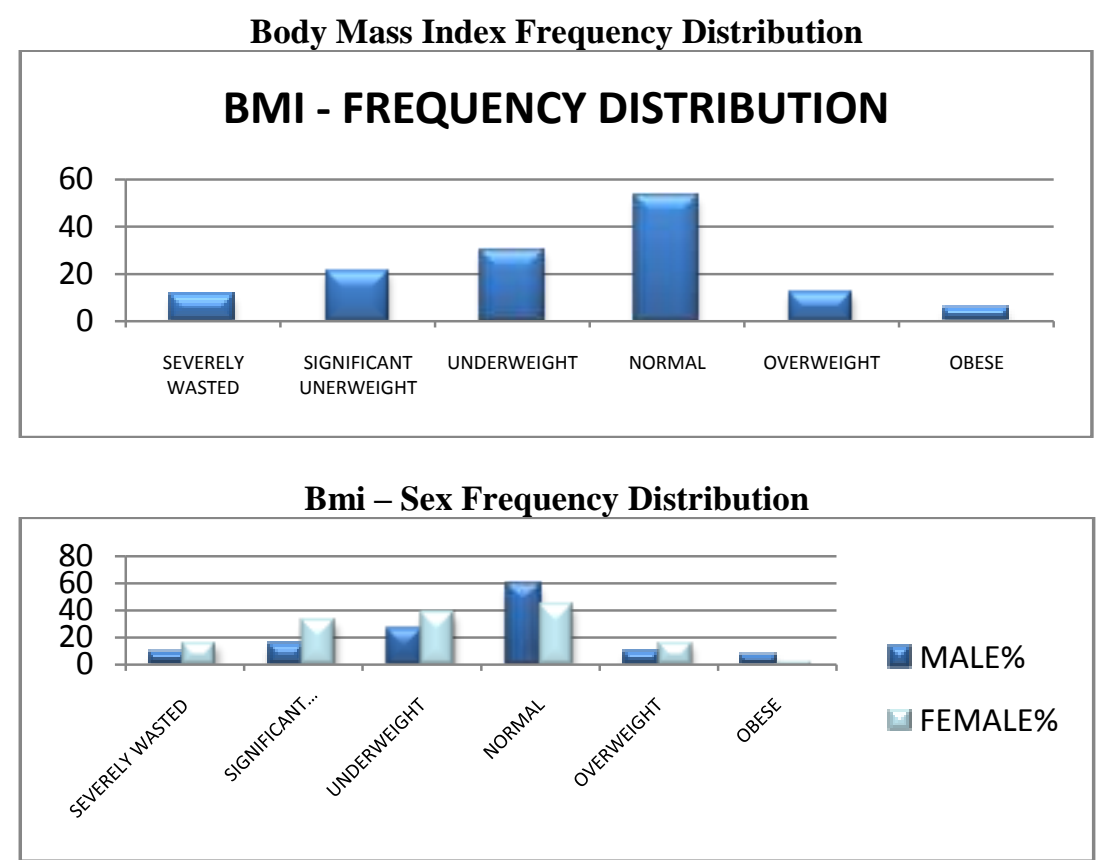

\begin{tabular}{|l|c|c|c|c|c|c|}
\hline \multirow{2}{*}{ RANGE } & \multicolumn{2}{|c|}{ MALE } & \multicolumn{2}{c|}{ FEMALE } & \multicolumn{2}{c|}{ TOTAL } \\
\cline { 2 - 7 } & NUMBERS & $\%$ & NUMBERS & $\%$ & NUMBERS & $\%$ \\
\hline$<16$ (Severely wasted) & 5 & $7.9 \%$ & 6 & $16.2 \%$ & 11 & $11 \%$ \\
\hline $\begin{array}{l}<17 \text { (Significant } \\
\text { underweight) }\end{array}$ & 9 & $14.3 \%$ & 12 & $32.4 \%$ & 21 & $21 \%$ \\
\hline$<18.5$ (Underweight) & 16 & $25.3 \%$ & 14 & $37.8 \%$ & 30 & $30 \%$ \\
\hline 18.5 to 24.9 (Normal) & 37 & $58.7 \%$ & 16 & $43.2 \%$ & 53 & $53 \%$ \\
\hline $\begin{array}{l}25 \text { to } \\
\text { (Overweight) }\end{array}$ & 6 & $9.52 \%$ & 6 & $16.2 \%$ & 12 & $12 \%$ \\
\hline$>30$ (Obese) & 4 & $6.34 \%$ & 1 & $2.7 \%$ & & 5 \\
\hline
\end{tabular}


After applying the WHO BMI classification $30 \%$ of the study group were found to be underweight, $21 \%$ were significantly underweight and $11 \%$ were severely wasted.

$37.8 \%$ of females were found to be underweight compared to $25.3 \%$ of males.

Clinical Stage Frequency Distribution

\begin{tabular}{|l|c|c|c|}
\hline CLINICAL STAGE & MALE & FEMALE & TOTAL \\
\hline STAGE 1 & 25 & 16 & 41 \\
\hline STAGE 2 & 7 & 6 & 13 \\
\hline STAGE 3 & 29 & 14 & 43 \\
\hline STAGE 4 & 2 & 1 & 3 \\
\hline
\end{tabular}

- $41 \%$ of the study group population were asymptomatic (Stage 1 )

- $43 \%$ of them were in the clinical stage 3.

- $\quad$ Only $3 \%$ were in the clinical stage 4 .
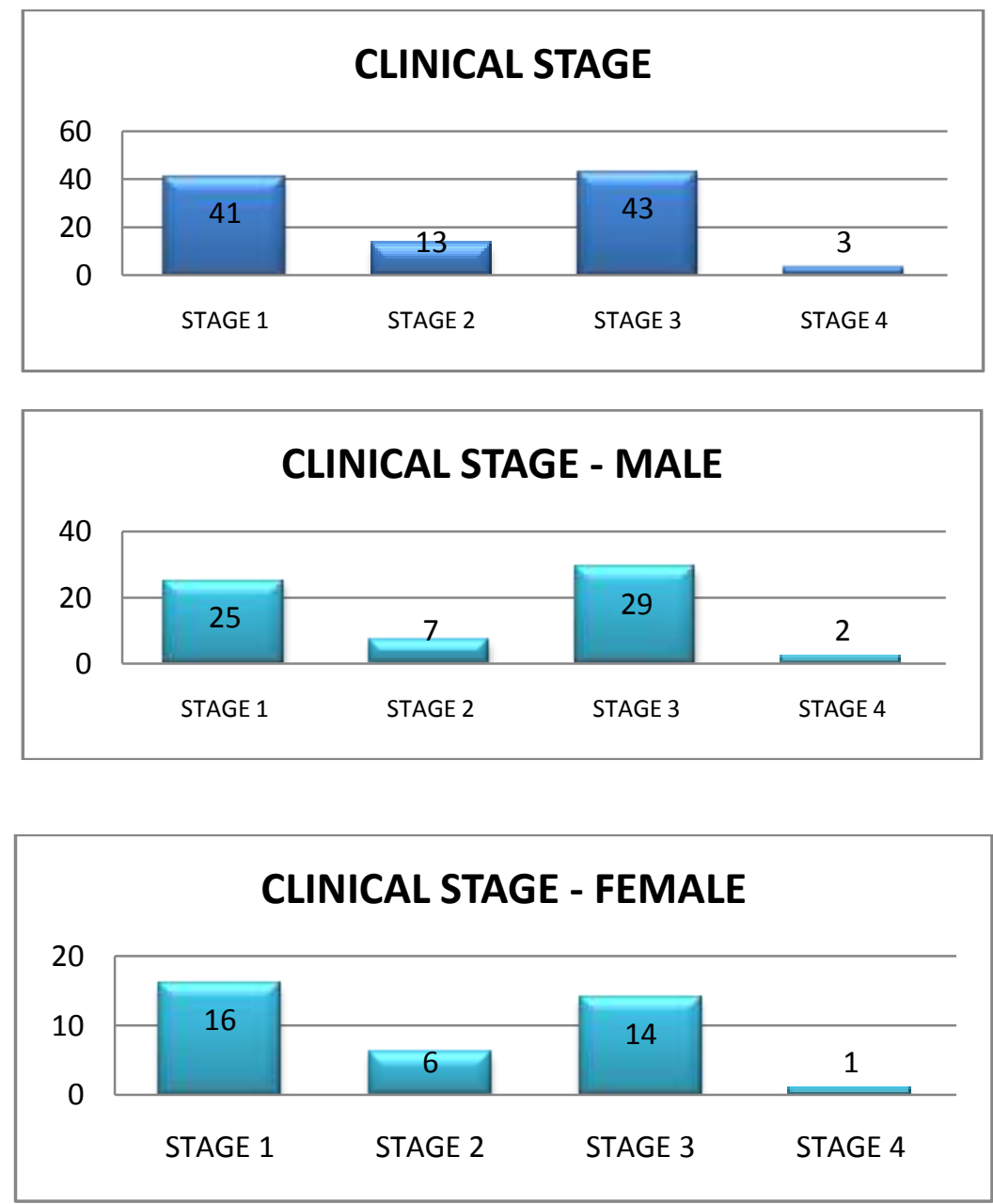

The distribution of clinical stage among males and females in the study population showed relatively similar trend.

Hiv Associated Immunodeficiecy Based On Cd4 Count

(Based on WHO immunological classification for established HIV infection)

\begin{tabular}{|l|c|c|c|c|}
\hline IMMUNODEFICIENCY & $\begin{array}{c}\text { CD4 } \\
\text { VALUE }\end{array}$ & MALE & FEMALE & TOTAL \\
\hline NOT SIGNIFICANT & $>500$ & 12 & 10 & 22 \\
\hline MILD & $\begin{array}{c}350- \\
499\end{array}$ & 10 & 8 & 18 \\
\hline ADVANCED & $\begin{array}{c}200- \\
349\end{array}$ & 19 & 8 & 27 \\
\hline SEVERE & $<200$ & 22 & 11 & 33 \\
\hline
\end{tabular}



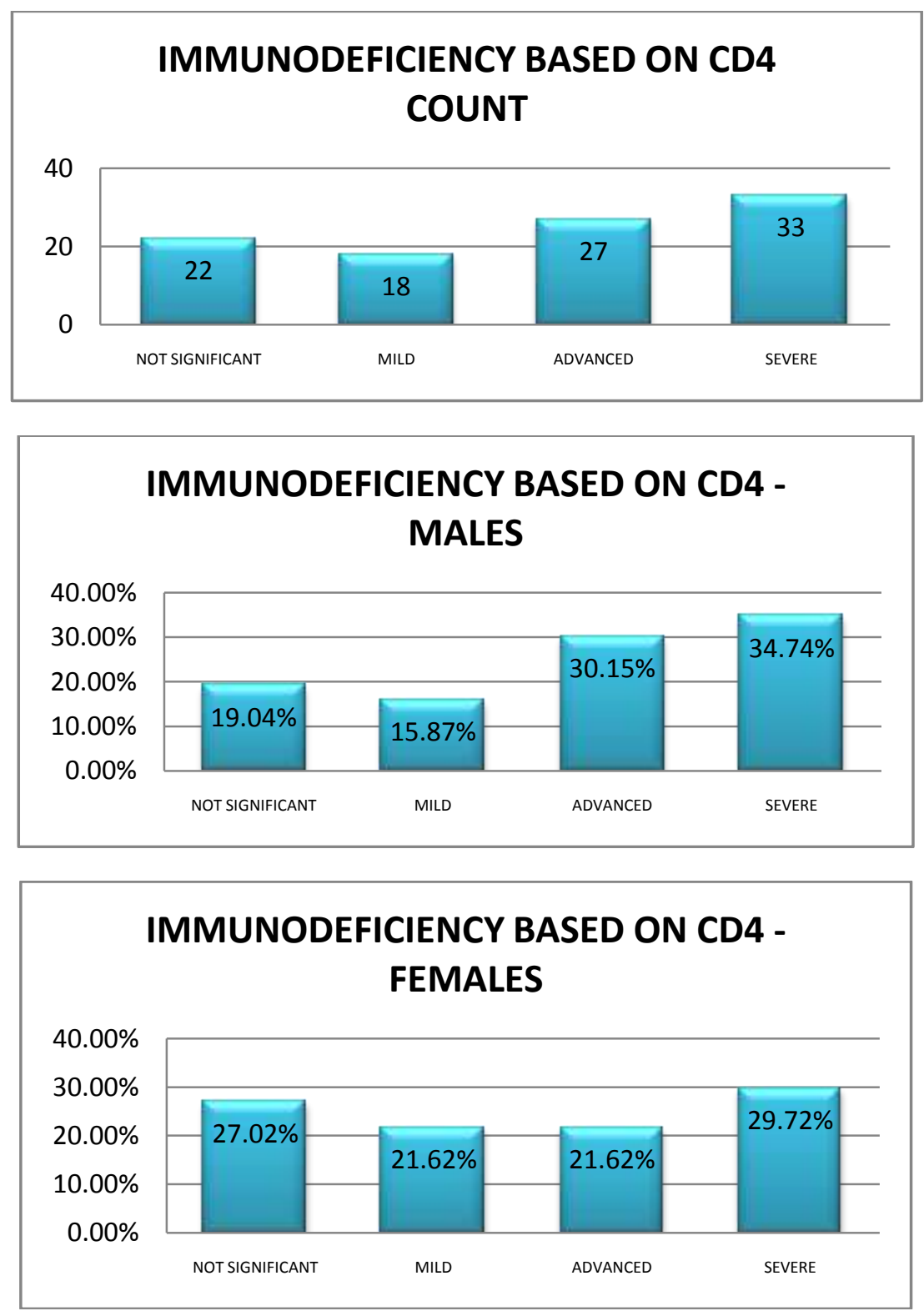

Although only three percentage of the study population fall into clinical stage 4, based on CD4 counts 33 percentage of study population are having severe immunodeficiency.

Distribution Of Immunodeficiency Among Various Clinical Stages

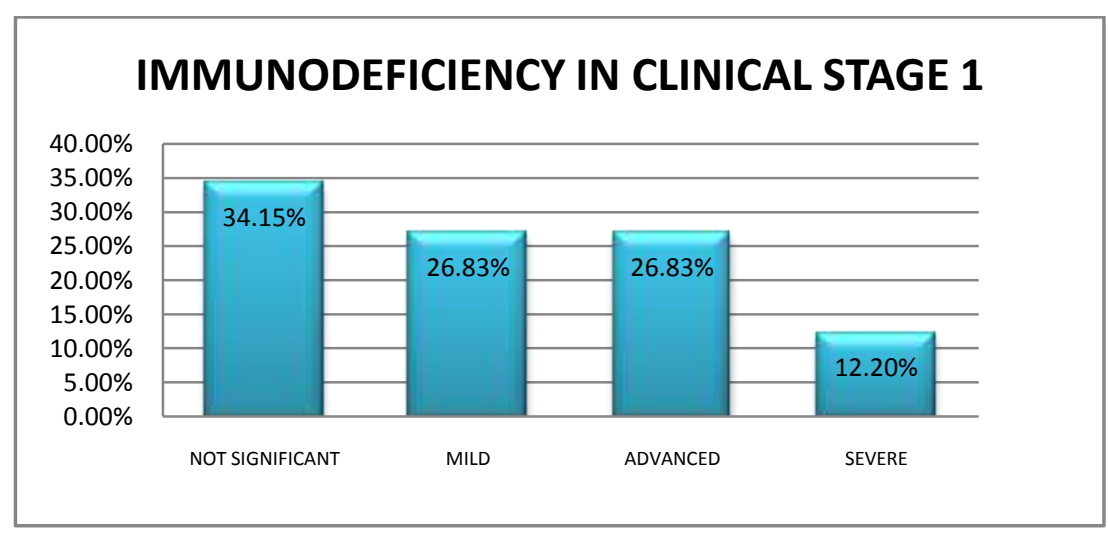


Majority of the patients in clinical stage 1 had either mild or non significant immunodeficiency. $12.2 \%$ of the patients, though in clinical stage 1 (asymptomatic) had severe immunodeficiency.
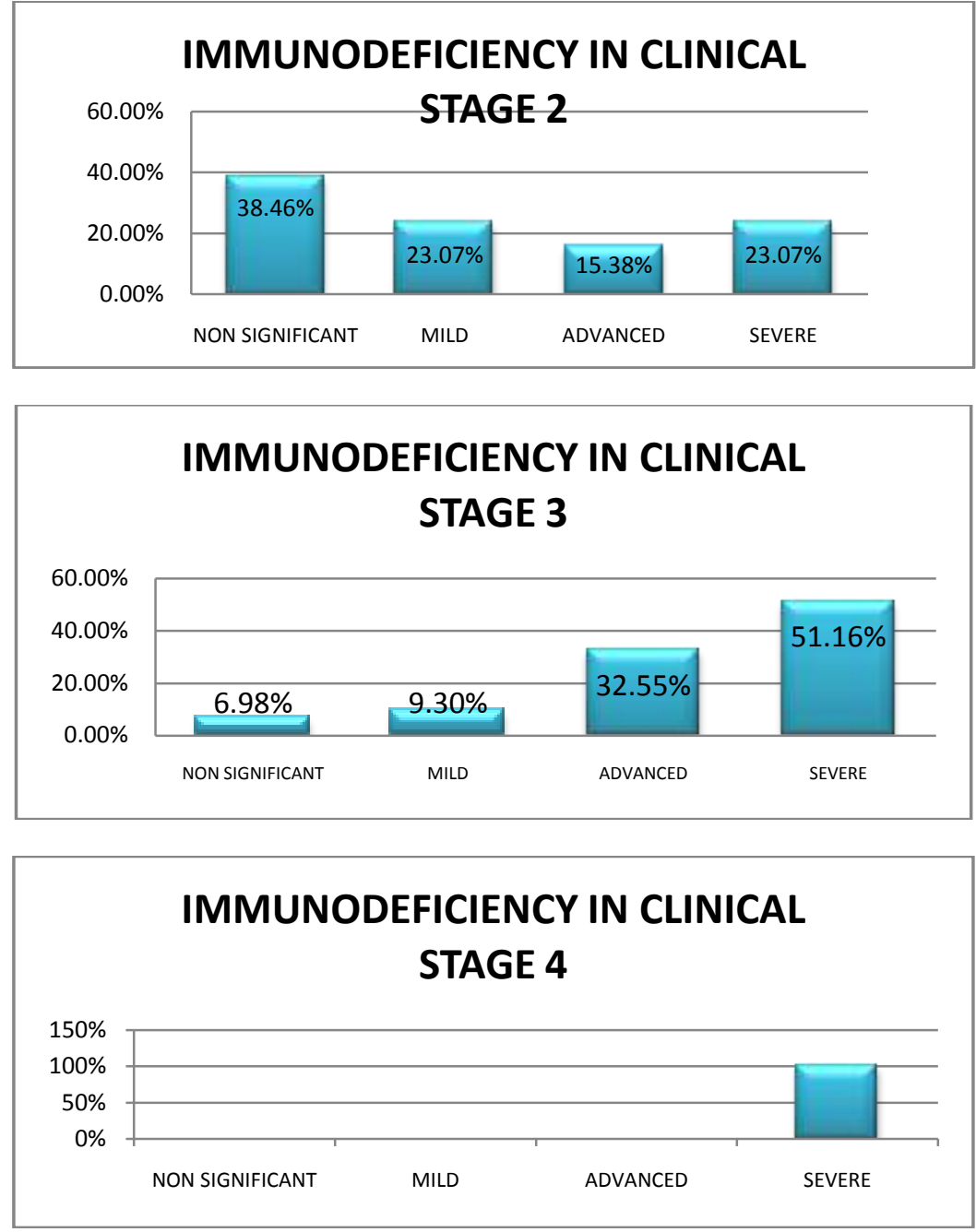

Moving from clinical Stage 1 to Clinical stage 4 there is an increase in patients in the advanced and severe immunodeficiency stage. The patients who had clinical stage 4 were all having severe immunodeficiency, suggesting a positive correlation between immunodeficiency based on CD4 count and clinical staging.

Disrtibution Of Anemia Based On Hemoglobin Values

\begin{tabular}{|l|c|c|c|}
\hline \multicolumn{1}{|c|}{ RANGE } & MALE & FEMALE & TOTAL \\
\hline NORMAL & 27 & 14 & 41 \\
\hline MILD ANEMIA & 25 & 4 & 29 \\
\hline MODERATE & 8 & 16 & 24 \\
\hline SEVERE & 3 & 3 & 6 \\
\hline
\end{tabular}

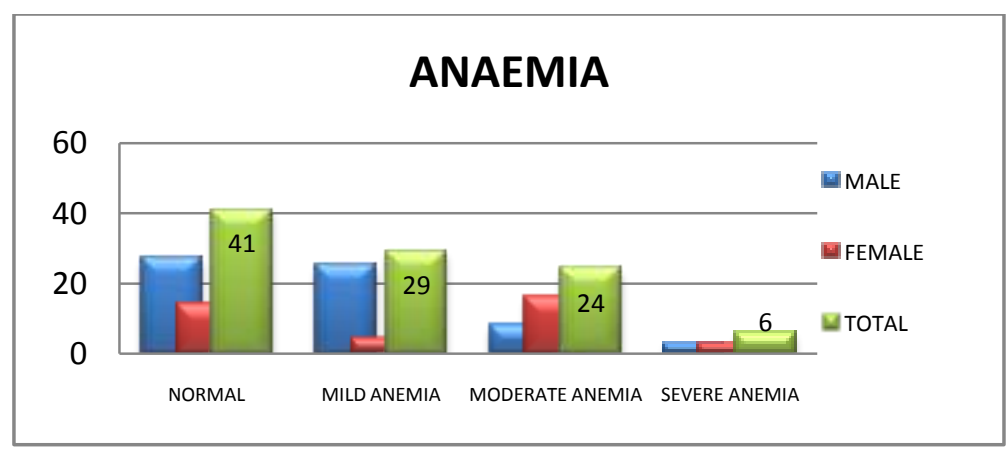


The prevalence of moderate to severe anaemia in study group was more in females compared to males. $51.35 \%$ of female patients had moderate to severe anaemia compared to $17.46 \%$ of male patients.

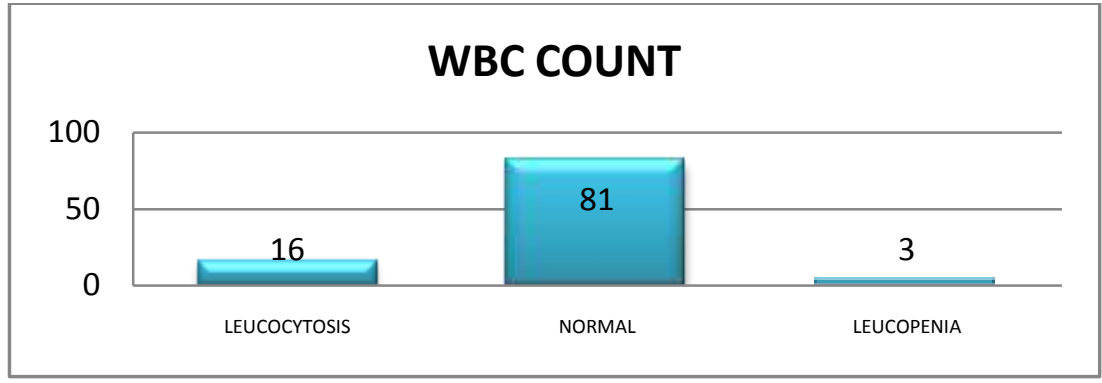

$16 \%$ of the study population had leucocytosis and $3 \%$ had leucopenia.

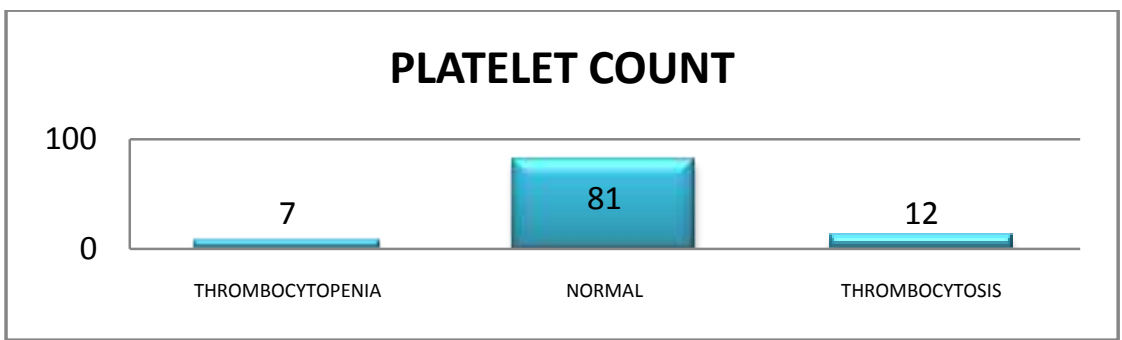

$7 \%$ of the study population had thrombocytopenia

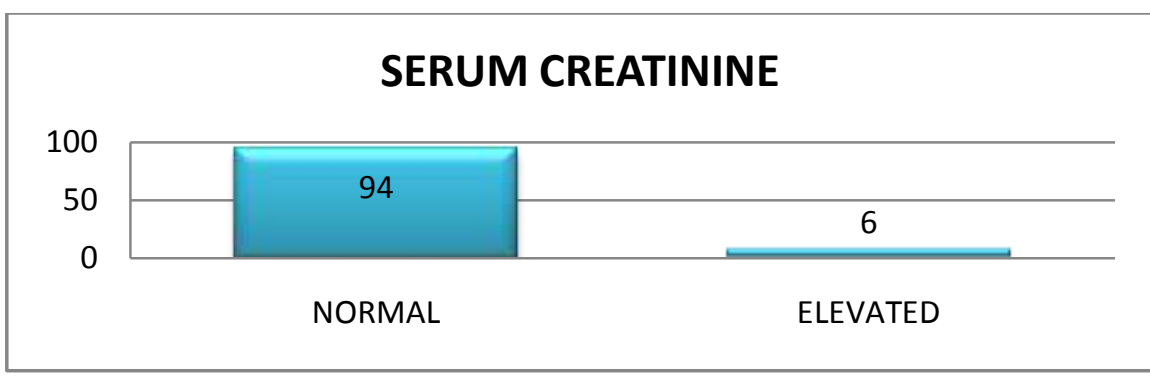

Serum creatinine was found to be elevated above normal limit in $6 \%$ of patients.

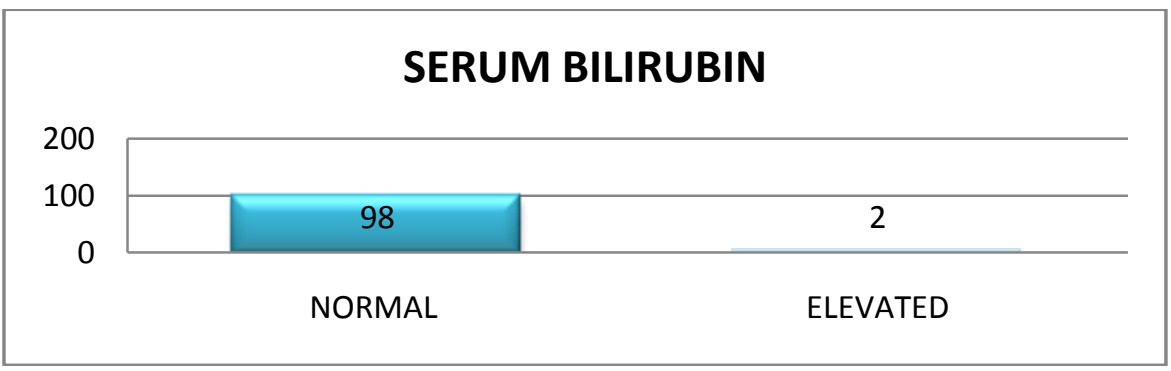

Serum bilirubin was found to be above the normal range in $2 \%$ of the patients.

Distribution Of Serum Transaminases Levels (Sgot And Sgpt)

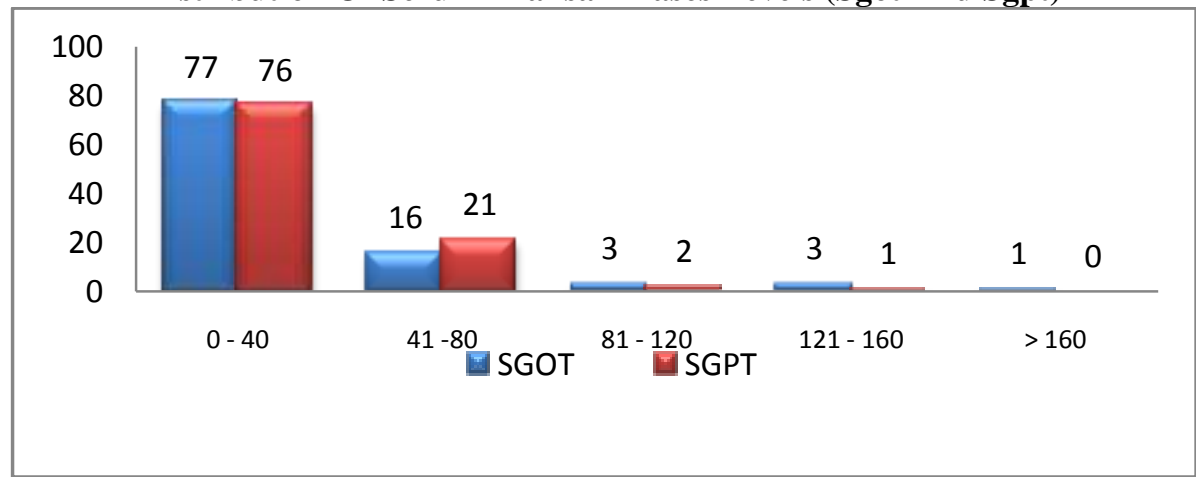


SGOT was found to be elevated in $23 \%$ of patients and it was above two times the upper limit of normal in $7 \%$ of patients SGPT was found to be elevated in $24 \%$ of patients. It was above two times upper limit of normal in $3 \%$ of patients.

\section{Symptomatology}

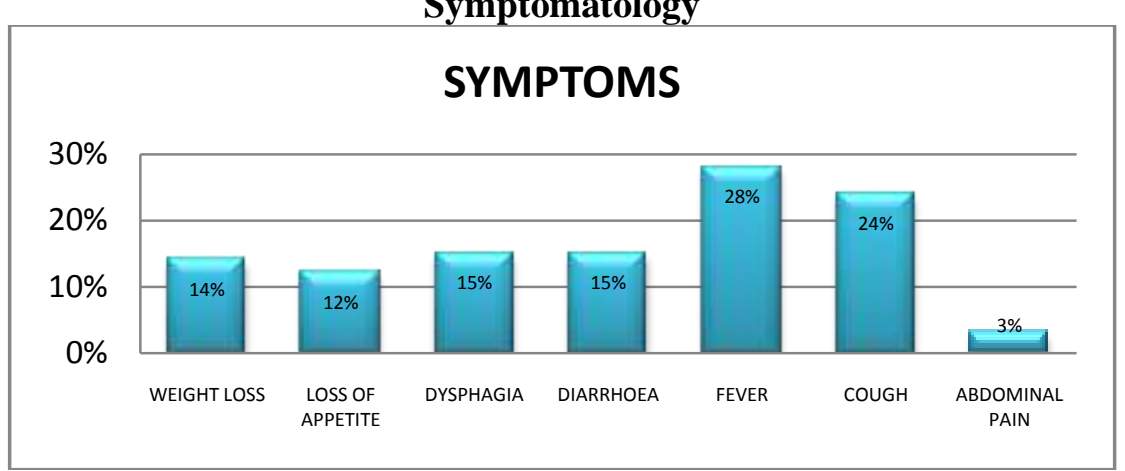

\begin{tabular}{|l|c|c|c|}
\hline \multicolumn{1}{|c|}{ SYMPTOMS } & MALE & FEMALE & TOTAL \\
\hline WEIGHT LOSS & 8 & 6 & 14 \\
\hline LOSS OF APPETITE & 8 & 4 & 12 \\
\hline DYSPHAGIA & 10 & 5 & 15 \\
\hline DIARRHOEA & 8 & 7 & 28 \\
\hline FEVER & 16 & 12 & 24 \\
\hline COUGH & 17 & 7 & 3 \\
\hline ABDOMINAL PAIN & 2 & 1 & \\
\hline
\end{tabular}
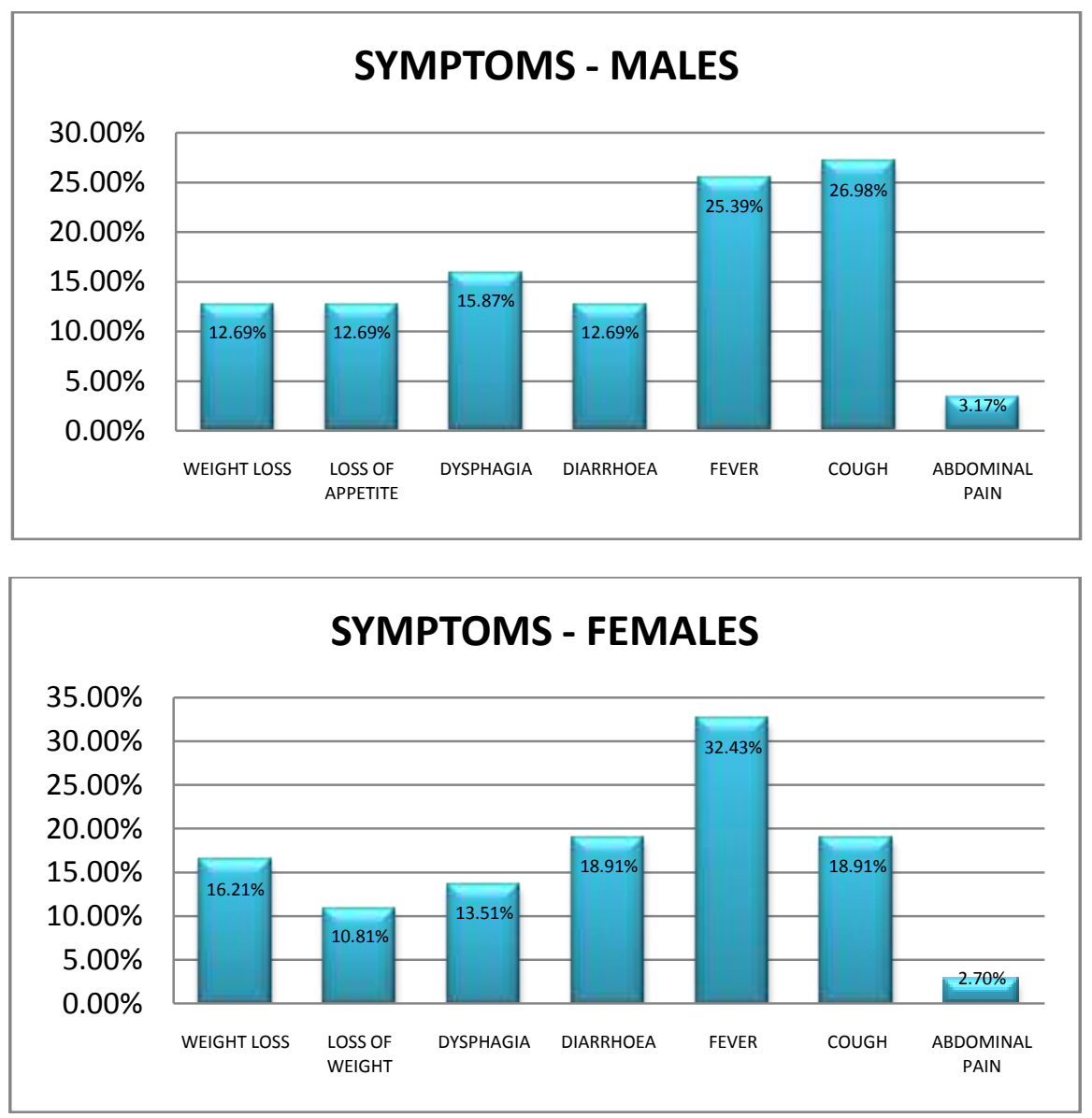

The most common symptom of the patients in the study population is fever (28\%), followed by cough (24\%), dysphagia (15\%), diarrhoea (15\%), eight loss $(14 \%)$, loss of appetite $(12 \%)$ and abdominal pain (3\%).Cough (26.98\%) was the predominant symptom among male patients, but the predominant symptom in the females was found to be Fever $(32.43 \%)$. 


\begin{tabular}{|c|c|c|c|c|}
\hline \multicolumn{5}{|c|}{ Opportunistic Infections - Frequency Distribution } \\
\hline \multicolumn{5}{|c|}{ OPPORTUNISTIC INFECTIONS } \\
\hline \multirow{2}{*}{$0 \%$} & $36 \%$ & & $\%$ & $1 \%$ \\
\hline & \multicolumn{4}{|c|}{ TUBERCULOSIS ORAL CANDIDIABISARRHOEAL DISEASEERPES ZOSTER } \\
\hline \multicolumn{2}{|c|}{ OPPORTUNISTIC INFECTIONS } & MALE & FEMALE & TOTAL \\
\hline \multicolumn{2}{|c|}{ TUBERCULOSIS } & 26 & 10 & 36 \\
\hline \multicolumn{2}{|c|}{ ORAL CANDIDIASIS } & 12 & 5 & 17 \\
\hline \multicolumn{2}{|c|}{ DIARRHOEAL DISEASE } & 8 & 7 & 15 \\
\hline \multicolumn{2}{|c|}{ HERPES ZOSTER } & 1 & 0 & 1 \\
\hline \multicolumn{2}{|c|}{ GENITAL CANDIDIASIS } & ----- & 1 & 1 \\
\hline
\end{tabular}
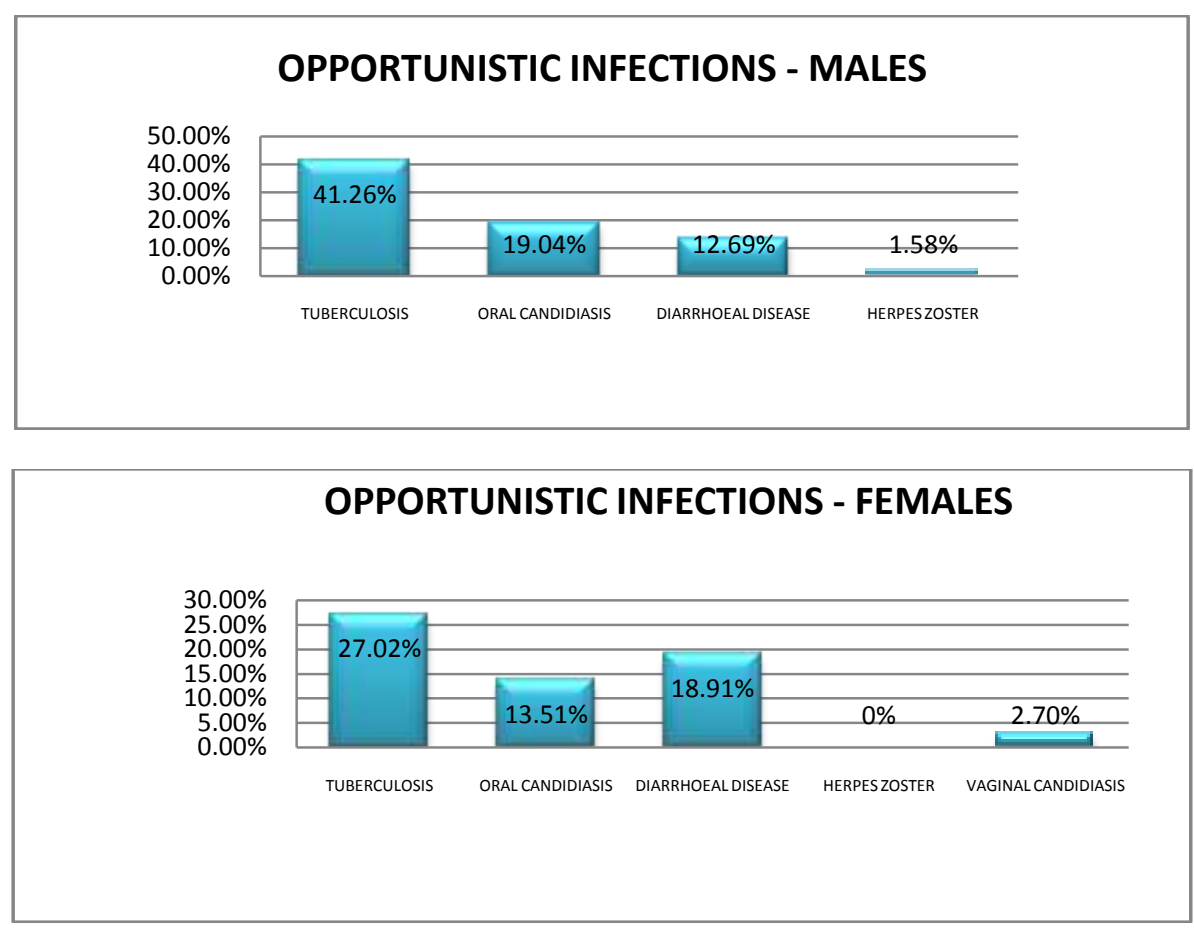

The commonest opportunistic infection related to HIV infection found in the study was Tuberculosis which was found in $36 \%$ of the study population. It was followed by Oral Candidiasis in 17\% of patients and Diarrhoeal disease in $15 \%$ of the patients.

\section{Discussion}

HIV/AIDS as already discussed has several clinical stages, variable pathogenesis and opportunistic infections. In this study, the clinical and laboratory profile of 100 patients, who were newly diagnosed were studied and documented. There were 63 male patients and 37 female patients in the study population. The majority of the newly diagnosed HIV patients belonged to the age group of 31 to 45 years, suggesting that the incidence and prevalence of the disease is more common in the sexually active period of life. $77 \%$ of the study population were literates and the rest were illiterates.

Body mass index distribution showed that $30 \%$ of the study population were under weight. Among them $21 \%$ were significantly underweight and $11 \%$ were severely wasted. These individuals may be part of HIV wasting syndrome. $37.8 \%$ of females were underweight compared to $25.3 \%$ of males.

WHO clinical staging and immunological classification were applied to the study population. $41 \%$ of the patients were in the clinical stage 1 and $43 \%$ in clinical stage 3 . Higher number of patients in clinical stage 3 is because of the higher prevalence of Pulmonary Tuberculosis co-infection. Another factor is that in Tirunelveli medical college all patients diagnosed with tuberculosis are screened for HIV and, if they tested positive they fell into the category of clinical stage 3. It also illustrates the importance of screening for HIV in patients with 
Tuberculosis and the vice versa. The clinical stage distribution showed a relatively similar trend in both males and females.

$33 \%$ of the study population had severe immunodeficiency (based on WHO immunological classification for established HIV infection). $60 \%$ of the population had advanced immunodeficiency or more. When this immunological classification was applied to patients in individual clinical stage, there was a increase in patients with advanced or severe immunodeficiency when moving from clinical stage 1 to clinical stage 4 as expected. All the three patients who were in clinical stage 4 were found to be having severe immunodeficiency. Though various studies suggest that CD4 alone cannot be a true indicator of the immunodeficiency in a HIV infected patient, in this study there is a positive correlation between the immunodeficiency classification based on CD4 count and clinical stage of the disease.

The prevalence of moderate to severe anaemia in the study population was $30 \% .51 .35 \%$ of females had moderate to severe anaemia compared to $17.46 \%$ in males. Hence there is increased prevalence of anemia in the female HIV infected patients, when compared to males. This may be explained by the fact that anemia is more prevalent in females than in males in this locality.

$16 \%$ of the study population had leucocytosis and $3 \%$ had leucopenia.7\% of the study population had thrombocytopenia. It is also important to note that unexplained anaemia $(<8 \mathrm{~g} / \mathrm{dl})$, neutropenia $(<0.5 \times 109$ per litre) or chronic thrombocytopenia $(<50 \times 109$ per litre), in a HIV infected patient is classified as clinical stage 3 according to WHO. So the cause of such haematological problems in a HIV infected patient should be investigated.

Serum creatinine was found to be elevated in $6 \%$ of patients. The presence of increased serum creatinine in a HIV positive patient may be due to either HIV itself (HIV associated nephropathy) or may be due to antiretroviral drugs. This study was conducted in HAART naïve patients, so there is no possibility of anti retroviral drugs induced renal failure in this study group. Also HIV infected individuals are more prone to prerenal azotemia due to volume depletion occurring from salt wasting, poor nutrition, nausea and vomiting. To find out the presence of HIV associated nephropathy additional investigations should be done like 24 hours urine protein to demonstrate nephrotic range of proteinuria and renal biopsy to prove the presence of focal segmental glomerulosclerosis.

Serum bilirubin was found to be elevated in $2 \%$ of the patients. Liver transaminase enzymes were elevated in $24 \%$ of patients. However SGOT and SGPT was elevated two times upper limit of normal only in $7 \%$ and $3 \%$ respectively. Such abnormality in HIV infected patients prompts the screening for hepatitis B or C co-infection in them. Many of the patients in this study who were found to be HIV infected were already taking anti tuberculous therapy for Tuberculosis. Elevated serum bilirubin and transaminase levels above 2 times upper limit of normal in such patients may be due to drug induced liver injury. Those with only transaminase elevation less than 2 times the upper limit of normal may be due to liver adaptation to anti tuberculous therapy.

The most common symptom in the study population was fever (28\%), followed by cough(24\%). Cough was the most common symptom in male patients, while in females fever was the most common symptom. Patel AK et al and Kothari $\mathrm{K}$ et al in their respective studies had already found fever as the commonest symptom. This proved to be true in this study also.

The commonest opportunistic infection in study population was pulmonary tuberculosis in $36 \%$ of the patients. It was followed by oral candidiasis (17\%) and diarrhoeal disease (15\%). According to Patel AK et al, the most common opportunistic infection was oral candidiasis followed by tuberculosis. Studies conducted by Vajpayee et al and Zaheer et al had shown that tuberculosis is the commonest opportunistic infection. Tuberculosis as the most common opportunistic infection in this study can be attributed to the high prevalence of tuberculosis in this locality.

\section{Conclusion}

Most of the newly diagnosed HIV infected patients belong to the age group of 31 to 45 years of age. There is a positive correlation between the clinical stage and the immunodeficiency based on CD4 count. Fever is the most common symptom in newly diagnosed HIV infected patients, followed by cough. Tuberculosis is the most common opportunistic infection followed by oral candidiasis. All patients with HIV infection should be screened for Tuberculosis and vice versa.

\footnotetext{
References

[1]. www.naco.gov.in/upload/.../NACO_English\%202013-14.pdf

[2]. http://www.thehindu.com/news/national/tamil-nadu/hiv-prevalence-among-adults-in-tn-continues-to-decline/article5409092.ece.

[3]. Zuckerman AJ, Banatvala JE, Griffiths PD, Schoub B, Mortimer P. Principles and Practice of Clinical Viology; 6th Ed. London: Wiley - Blackwell; 2008

[4]. Abbas AK. In: Kumar V, Abbas AK, Fausto N, editors. Robbins and Cotran: Pathologic Basis of Disease; 7th Ed. New Delhi; 2004: pp 245-58.

[5]. Coleman CM, Li Wu. HIV interactions with monocytes and dendritic cells: viral latency and reservoirs. Retrovirology $2009 ; 6$ : 51.
} 
[6]. Johnson VA, Brun-Vezinet F, Bonaventura C, et al. Update of the drug resistance mutations in HIV1. Top HIV Med 2009; 17: 13845.

[7]. Joshi VV. Pathology of AIDS and Other Manifestations of HIV Infection. Tokyo: Igaku Shoin Medical Publishers; 1990: pp 23969.

[8]. Lane HC. Pathogenesis of HIV infection: total CD4+ T-cell pool, immune activation, and inflammation. Top HIV Med 2010; 18: 26.

[9]. Mosier DE. How HIV changes its tropism: evolution and adaptation. Curr Opin HIV AIDS 2009; 4: 125-36.

[10]. Robertson M. What we still do not know about AIDS? J Biol 2009

[11]. Shackett BL, Anton PA. HIV infection and gut mucosal immune function: updates on pathogenesis with implications for management and intervention. Curr Infect Dis Rep 2010; 12: 19-27.

[12]. Sharma D, Bhattacharya J. Cellular and molecular basis of HIV-associated neuropathogenesis. Ind J Med Res 2009; 129: 637-51.

[13]. Bartlett JG, Gallant JE. Medical Management of HIV infection. John Hopkins University School of Medicine, Maryland, USA. 2009. http://www.hopkinsaids. edu

[14]. National Guidelines on Second line ART for Adults and Adolescents (Draft). (October 2008). National AIDS Control Organisation, Ministry of health and Family Welfare, Government of India. Available at: www.nacoonline.org

[15]. Clinical Profiles of HIV-Infected, HAART-Naive PatientsAdmitted to a Tertiary Level Hospital in Maseru, Lesotho K Thinyane, V Cooper

[16]. Clinical Profile of HIV/AIDS-infected Patients Admitted to a New Specialist Unit in Dhaka, Bangladesh-A Low-prevalence Country for HIV Nashaba Matin, Lubaba Shahrin, Mohammed Moshtaq Pervez, Sayera Banu, Dilruba Ahmed, Mahmuda Khatun, and Mark Pietroni

[17]. Clinical Profile of HIV/Aids Patients in Srinagar, Kashmir, India Kaiser Ahmed Wani

[18]. Clinico-epidemiological profile of HIV patients attending ART centre in rural Western Maharashtra, India

[19]. Jayant D. Deshpande1, Purushottam A. Giri2, Deepak B Phalke3 